\title{
Investigation of Ventilation Behaviors in Mechanically Ventilated Residential Buildings in China
}

\author{
Yue $\mathrm{Qi}^{1}$, Junjie $\mathrm{Liu}^{1}$, Xilei $\mathrm{Dai}^{1}$, Lei Zhao ${ }^{1}$, Dayi $\mathrm{Lai}^{2, *}$, and Shen $\mathrm{Wei}^{3}$ \\ ${ }^{1}$ Tianjin Key Laboratory of Indoor Air Environmental Quality Control, School of Environmental Science and Engineering, Tianjin \\ University, Tianjin 300072, China \\ ${ }^{2}$ Department of Architecture, School of Design, Shanghai Jiao Tong University, Shanghai 200240, China \\ ${ }^{3}$ The Bartlett School of Construction and Project Management, University College London (UCL), London, WC1E 7HB, UK
}

\begin{abstract}
Mechanical ventilation system provides a more reliable, controllable, and comfortable way of ventilation than natural ventilation through an opened window. However, the operation of mechanical ventilation system cost energy. This study investigated the usage of natural and mechanical ventilation in 46 apartments in ten cities across five different climate zones in China by on-site monitoring and questionnaire survey. On average, the daily natural and mechanical ventilation durations were 11 hours and 7.2 hours, respectively. Large differences existed among climate regions and seasons. From north to south, as the climate became warmer, the usage of natural ventilation increased. From seasonal perspectives, natural ventilation duration was the longest in summer and the shortest in winter. The trend of mechanical ventilation usage was opposite to that of natural ventilation. Generally, as the outdoor air temperature increased, the duration of natural ventilation increased and the duration of mechanical ventilation decreased. This study proposed an outline to use thermal comfort, health, and energy saving as three motivations to analyze ventilation behaviors. Based on the obtained results, suggestions were made for achieving healthy, thermally comfortable, and energy efficient ventilation in residential buildings.
\end{abstract}

\section{Introduction}

By supplying outdoor air and removing indoor air in buildings, ventilation can create a thermally comfortable indoor environment with acceptable indoor air quality (IAQ) [1]. Ventilation can be achieved by natural forces such as wind and thermal pressures through window openings or by artificial means through mechanical ventilation systems [2].

A number of researchers, such as Rijal [3, 4], Andersen [5], and Pan [6] found that the proportion of opening windows was low under cold outdoor climate conditions, due to the thermal comfort considerations [611]. In cold climate, the reduced window opening duration may not provide sufficient ventilation to maintain an acceptable indoor air quality. Mechanical system provides a more reliable, controllable, and comfortable way of ventilation than opening windows. The mechanical fan can be operated continuously to ensure reliability, filter can be used to provide control over outdoor pollutants, and heat recovery unit can be used to reduce thermal discomfort.

Although mechanical ventilation offers several advantages over natural ventilation, it requires energy to operate. As a result, it is interesting to study how people actually choose between mechanical ventilation and natural ventilation, if both options are available. Park and Kim [12] studied the mechanical ventilation behavior in apartments in South Korea on November and the December of 2008 by questionnaire survey. They found that 95 out of $139(68.3 \%)$ respondents did not use mechanical ventilation at all during the heating period in winter, and the major reason for not using the mechanical ventilation system is the increase in heating energy cost. The authors only conducted the measurement in winter in cold climate South Korea and window operation behavior was not recorded. In addition, the questionnaire survey method may not reflect realistic situations because the answers from respondents may be inaccurate and biased.

This paper reports the findings of a year-long field measurement of ventilation behavior in apartments with mechanical ventilation across five different climate zones in China. On the basis of the acquired information, a framework for analyzing the ventilation behavior in residential buildings was proposed, and suggestions for achieving healthy, thermally comfortable, and energy efficient ventilation were proposed.

\section{Methods}

In order to collect data to analyze the ventilation behavior, a measurement campaign was conducted in 46 apartments across five climate zones in China. This section describes the measurement campaign, the climate

\footnotetext{
* Corresponding author: dayi_lai@sjtu.edu.cn
} 
and season division in each monitored climate zone, and the data acquisition in the monitored apartments.

\subsection{Measurement campaign}

The one-year field campaign was carried out from January 1, 2017 to December 31, 2017 in 46 apartments equipped with mechanical ventilation system across five climate zones in China. The classification of climate zones in this study was based on thermal design code for civil buildings in China (GB50176-2016) [13]. The code defines five climate zones, namely, severe cold (SC), cold (C), hot summer and cold winter (HSCW), mild (M), and hot summer and warm winter (HSWW), on the basis of the average air temperatures in the coldest and hottest month. As shown in Figure 1, the monitored apartments were coming from Urumqi, Shenyang, Yingkou, Tianjin, Xi'an, Shanghai, Kunming, Guangzhou, Shenzhen, and Nanning. In the monitored apartments, ventilation can be achieved by either opening windows, i.e. natural ventilation, or by operating a mechanical ventilation system.

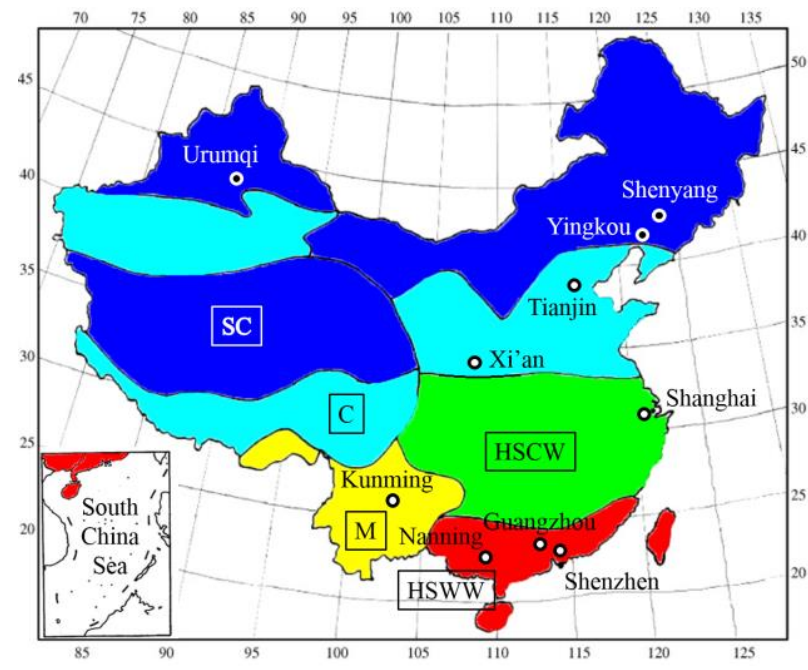

Fig. 1. Illustration of the five climate zones and the monitored cities on map of China.

The mechanical ventilation system installed in the 46 monitored apartments can be characterized into three types: exhaust ventilation system, supply ventilation system, and energy recovery ventilation system [14]. Energy recovery ventilation has a heat exchanger that warms the cold air outside using the exhaust indoor air. The number of monitored households were 13, 14, 7, 7, and 5 for the SC, C, HSCW, M, and HSWW regions, respectively. The mechanical ventilation systems in all monitored apartments in SC and HSCW regions were energy recovery system, and all the monitored apartments in HSWW regions used supply ventilation system.

\subsection{Season division}

In order to consider the outdoor temperature difference in various climate zones, the division of season was on the basis of mean daily air temperature according to the
Chinese national standard QX/T 152-2012: Definition of climatic season [15]. According to this standard, winter begins and ends when the five-day averaged air temperature is less than and greater than $10{ }^{\circ} \mathrm{C}$, respectively, while summer starts and terminates when the five-day averaged air temperature is higher than and lower than $22{ }^{\circ} \mathrm{C}$, respectively. Spring and autumn occur between winter and summer. The cities in SC region have long winter and short spring, summer and autumn. Kunming from $\mathrm{M}$ region have no summer and fall, while cities from HSWW region have no winter.

\subsection{Data acquisition}

\subsubsection{On-site monitoring}

Four categories of parameters were collected, including the mechanical ventilation operation status, the windowopening and closing actions and relevant indoor and outdoor environmental parameters.

The mechanical ventilation operation status was obtained via a self-designed recorder with a differential pressure meter and a data transmitter. The windowopening and closing actions in the main bedroom were recorded by magnetic sensors manufactured by Xiaomi Inc. The window status was considered as closed when all windows were closed, and open when any of the windows were open. Two-hour average outdoor air temperature $\quad\left({ }^{\circ} \mathrm{C}\right)$ was obtained from www.weather.com.cn. The indoor environmental parameters, including the indoor air temperature, indoor relative humidity, and $\mathrm{CO}_{2}$ concentration, were monitored via an environmental monitoring kit manufactured by iKair at a 1-minute interval. The environmental monitoring kits were placed on the night table near the bed. In order to determine if the room was occupied, the bedroom $\mathrm{CO}_{2}$ (ppm) was monitored at a 1minute interval via an environment monitoring kit by iKair. If on one day, the $\mathrm{CO}_{2}$ concentration did not exceed $460 \mathrm{ppm}$, and the window status did not change, and the mechanical ventilation was not operating, then the room was deemed as unoccupied on that day. The $460 \mathrm{ppm}$ is chosen by summing the outdoor $\mathrm{CO}_{2}$ concentration (420 ppm) [8] and the instrument uncertainty (40 ppm). Data from unoccupied days were excluded from our analysis.

\subsubsection{Questionnaire survey}

The questionnaire was used to collect subjective choices about residents' ventilation behaviors and the reasons behind their behaviors. The first part of the questionnaire consists of four questions that ask the preferred type of ventilation of residents under cold, comfortable, and hot outdoor climate, and under serious outdoor pollution condition. The second section has two questions that let the respondents provide one or several reasons when not using mechanical system or windows for ventilation. The questionnaire was sent via a link to the cellphones of the residents from the monitored households. A total of 38 questionnaires were collected. 


\section{Results}

This section first presents the ventilation durations for different climate regions. Then, the natural and mechanical ventilation durations with respect to outdoor temperature were further demonstrated. Next, the impact of system type on mechanical ventilation behavior was examined, and the ventilation behavior pattern among households was analyzed. Finally, the result of the questionnaire survey was presented.

\subsection{General ventilation duration}

\subsubsection{Daily average ventilation duration for the whole year}

Figure 2 shows the daily average durations for natural ventilation (Figure 2(a)) and mechanical ventilation (Figure 2(b)) in various climate zones for the whole year. The average values of daily durations for $\mathrm{NV}$ and $\mathrm{MV}$ for all apartments were 660 minutes (11.0 hours) and 429 minutes (7.2 hours), which indicates that on a general level, although mechanical ventilation is available in these monitored apartments, opening windows were the preferred way of ventilation for most of the households. In general, from north to south, as the climate became warmer, the natural ventilation duration increased and the mechanical ventilation decreased.

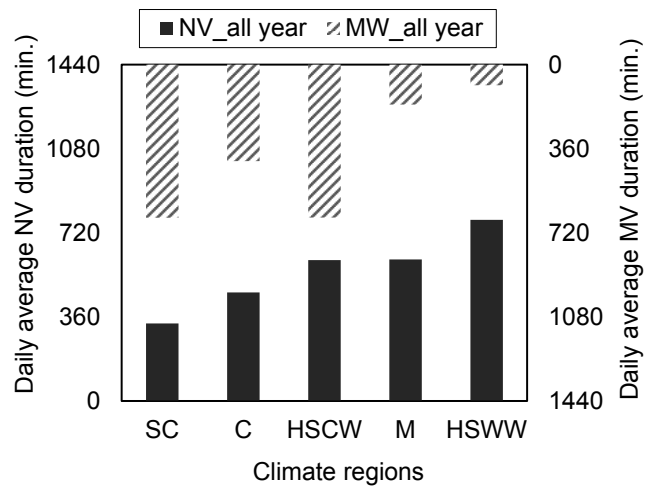

Fig. 2. Averaged daily ventilation duration for the whole year in different climate regions for natural ventilation and mechanical ventilation.

In the studied apartments in this investigation, the residents in cold climates compensated the reduced natural ventilation duration by operating mechanical ventilation systems. For climate regions with suitable climates for natural ventilation, such as $\mathrm{M}$ and HSWW, the mechanical ventilation durations were very low compared to other climate regions. It is also interesting to find that, although the climate of HSCW region was not as cold as SC region, the monitored apartments in HSCW used as much as MV compared to the monitored apartments in SC region. It is noteworthy that the averaged $\mathrm{MV}$ duration for the $\mathrm{C}$ region was noticeably shorter than those of the SC and HSCW regions. Five out of the 14 monitored apartments in $\mathrm{C}$ region used supply ventilation system, which could cause thermal discomfort and reduce the overall usage. The reason may be due to the income of residents. According to the National Bureau of Statistics of China [16], the 2016 annual disposable income of urban residents per capita of Shanghai, Shenyang, Urumqi, and Yingkou are 8552 U.S. Dollar, 5348 U.S. Dollar, 4670 U.S. Dollar, and 4028 U.S. Dollar, respectively. The higher income of residents in Shanghai in HSCW region made them less sensitive to the energy cost of mechanical ventilation systems compared to residents in SC cities.

\subsubsection{Daily average ventilation duration for the different seasons}

Figure 3 shows a clear seasonal pattern in natural ventilation and mechanical ventilation duration. Generally, summer and winter was the seasons with the longest and shortest natural ventilation duration, respectively. The seasonal climate difference attributed to the variations in seasonal ventilation durations. To compensate the reduced natural ventilation in winter, the duration of mechanical ventilation in winter was usually long. Summer generally had the shortest MV duration among all seasons. The NV durations in spring were shorter than those in autumn, and the MV durations in spring were longer than those in autumn. When seasons changed, people need time to adapt their behavior, so their ventilation behaviors in a new season followed the previous season. In other words, the ventilation duration in spring followed the trend in winter, and autumn followed summer.

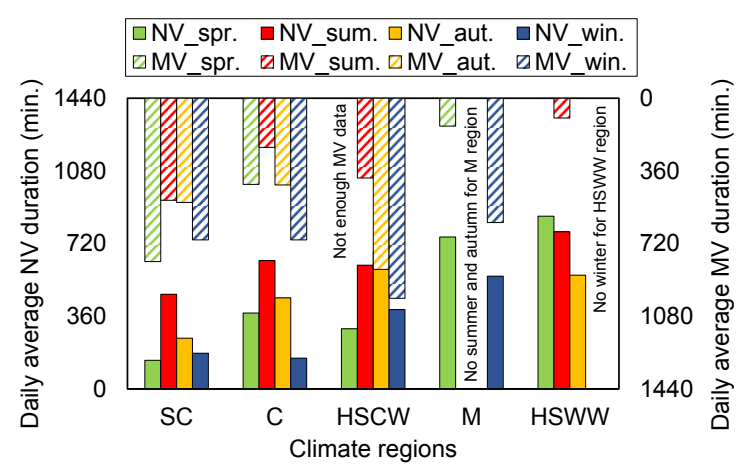

Fig. 3. Averaged daily ventilation duration for different seasons in various climate regions for natural ventilation and mechanical ventilation.

\subsection{The influence of outdoor air temperature on ventilation durations}

\subsubsection{The influence of outdoor air temperature on natural ventilation durations}

Figure 4 plots the daily mean natural ventilation duration against daily mean outdoor air temperature, by computing the average NV duration for every $2 \mathrm{~K}$ daily mean outdoor air temperature. 


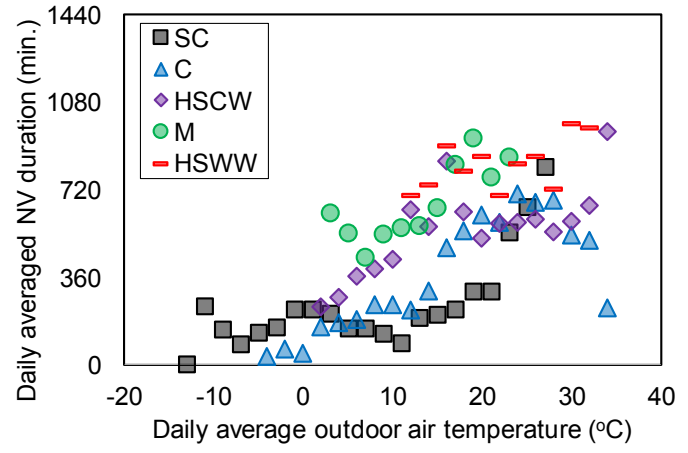

Fig. 4. Natural ventilation durations under different daily average outdoor air temperatures in different climate regions.

The window opening duration increased as the outdoor became warmer. For $\mathrm{C}$ regions, the duration started to decrease when the daily mean outdoor air temperature was larger than $24{ }^{\circ} \mathrm{C}$. When examining the natural ventilation duration under the same daily average outdoor air temperature for various climate regions, it is interesting to find that the NV duration increased from north to south, which corresponds to the findings of our previous study [17]. This regional difference in NV duration may be the result of residents' long-term exposure to the environment. For example, in the long and cold winter, residents in SC region tend to close their windows to avoid serious cold discomfort. When the outdoor climate became warmer, it was slow for the residents in SC region to change their habit and open window for longer period.

\subsubsection{The influence of outdoor air temperature on mechanical ventilation durations}

Figure 5 demonstrates the daily average mechanical ventilation duration against the daily average outdoor air temperature. Opposite to the relationship between outdoor air temperature and natural ventilation duration, the daily average MV duration decreased as the daily average outdoor air temperature increased. When the outdoor air temperature was suitable, people preferred $\mathrm{NV}$ over MV to reduce energy cost. Under the same daily average air temperature, obvious differences in the MV duration among climate regions can be observed. However, the trend of MV duration among climate zones was not as clear as that of NV duration. Two factors have been illustrated in Section 3.1. For SC region, the decrease rate of $\mathrm{MV}$ duration against the daily average outdoor air temperature was not as fast as the decrease rates in other regions. The larger inertia of SC residents in changing $\mathrm{MV}$ behavior corresponded to their slower adaption of window-opening behavior.

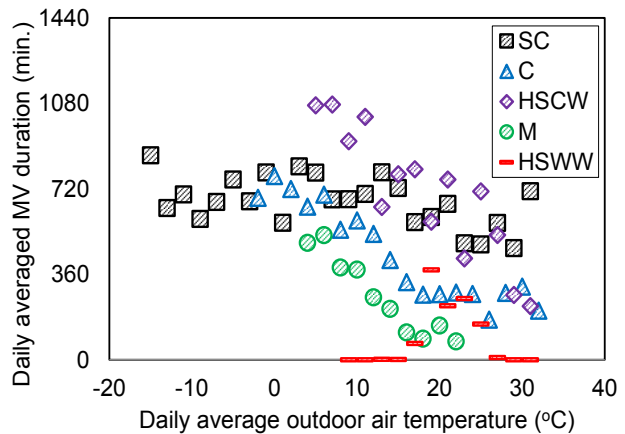

Fig. 5. Mechanical ventilation durations under different daily average outdoor air temperatures in different climate regions.

\subsection{Impact of different types of system on mechanical ventilation duration}

Two types of mechanical ventilation systems, supply system $(\mathrm{N}=5)$ and energy recovery system $(\mathrm{N}=9)$, were used in the monitored apartments in cold climate region. Figure 6 examines the impact of types of mechanical ventilation system on the ventilation duration against daily average outdoor air temperature. Figure 6(a) demonstrates that the average natural ventilation durations for the two types of apartments were similar. However, large difference was observed for the mechanical ventilation durations between the supply and energy recovery systems, as shown in Figure 6(b). Energy recovery ventilation systems were heavily used under cold outdoor temperature, and the usages decreased when the outdoor became warm. In comparison, the supply ventilation system was seldom used under cold weather, but a slight increase can be found when the daily average outdoor air temperature surpassed $18{ }^{\circ} \mathrm{C}$. The infrequent usage of supply system is reasonable because directly introducing the cold outdoor air into the building would cause thermal discomfort.
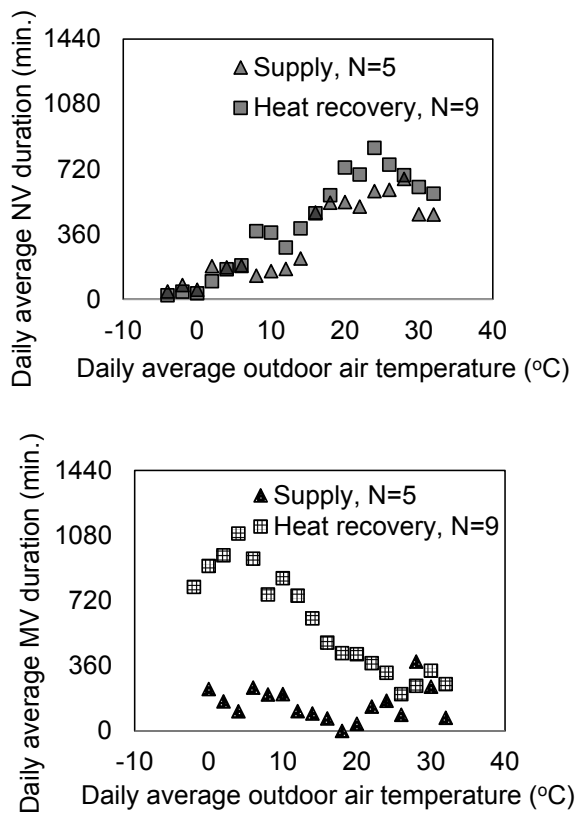
Fig. 6. Comparison of average ventilation duration between supply and energy recovery ventilation systems in cold climate region for (a) natural ventilation duration; (b) mechanical ventilation duration.

\subsection{Usage patterns of natural and mechanical ventilations}

Figure 7 shows the box plots of daily natural and mechanical ventilation durations in each monitored apartment. Large inter-family difference was found, especially for mechanical ventilation duration. For example, as demonstrated in Figure 7(b), within the 13 monitored apartments in SC regions, the median mechanical ventilation duration for four of the apartments was almost 1440 minutes, while the value for five of the apartments was near zero minutes. The natural ventilation durations among households also had a large discrepancy, although not as large as that of the mechanical ventilation duration. In addition to the large inter-family difference, the day-to-day variation in ventilation duration for some families were also huge, as shown by the large range of some of boxes in Figure 7.
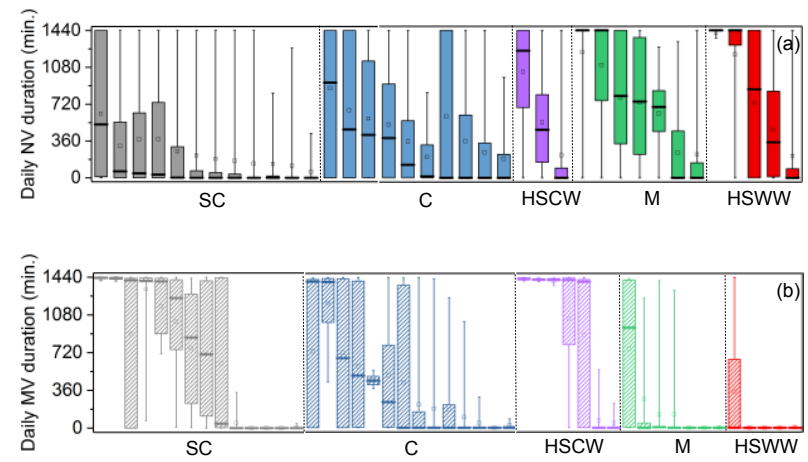

Fig. 7. Box plots of ventilation durations in each monitored apartment for (a) natural ventilation and (b) mechanical ventilation. The horizontal lines and the dots within the boxes denote the median and mean values. The bottoms and tops of the boxes represent the 25 th and 75 th percentiles, respectively, while the lower and upper ends indicate the 5th and 95th percentiles, respectively.

\subsection{Questionnaire survey}

\subsubsection{Answers on ventilation choice under different outdoor climate}

Figure 8 summarizes the answers of occupants' ventilation preference under cold, neutral, and hot outdoor air temperature. When the outdoor is cold or hot, most of the residents in $\mathrm{SC}, \mathrm{C}$, and $\mathrm{HSCW}$ regions preferred mechanical ventilation, while the outdoor is thermally comfortable, most of them preferred natural ventilation. In contrast, most of residents in $\mathrm{M}$, and HSWW regions preferred natural ventilation by opening windows, although the percentage of residents preferring natural ventilation slightly decreased under cold and hot outdoor climates. It should be noted that the questionnaire does not provide a quantitative indication of "cold", "neutral", and "hot" outdoor air temperature, the interviewees from different climate zones may have their own understandings.

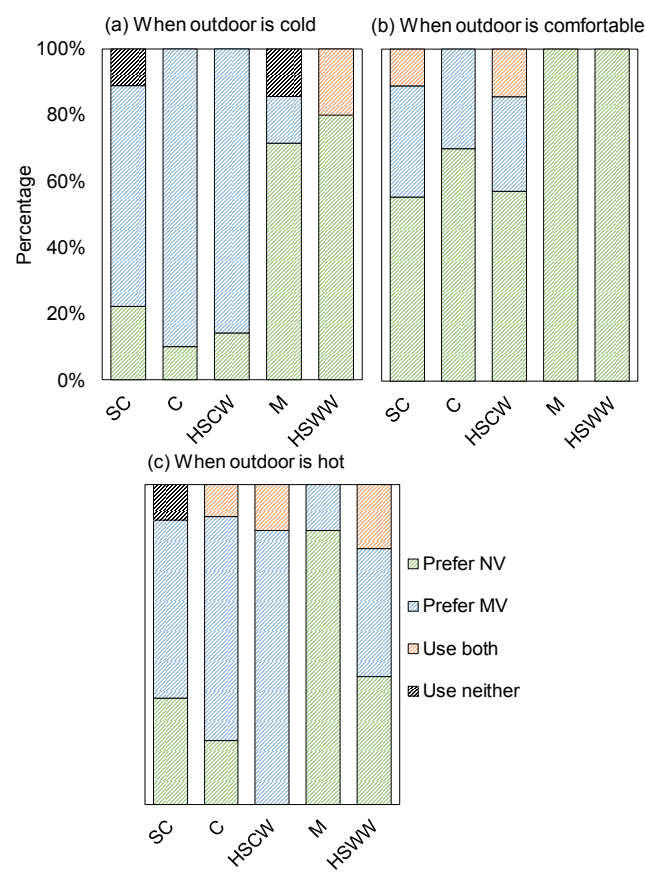

Fig. 8. Box plots of ventilation durations in each monitored apartment for (a) natural ventilation and (b) mechanical ventilation.

One noticeable difference between the monitored and surveyed results was people's ventilation pattern under hot outdoor climate. According to the answers from questionnaires, most residents prefer mechanical ventilation when the outdoor air temperature is high, but no rise in the actual mechanical ventilation duration was found as the daily average outdoor temperature increased.

\subsubsection{Answers on ventilation choice under different outdoor climate}

When using natural ventilation by opening windows, outdoor pollutants can directly enter indoor via open windows. Filter in mechanical ventilation system can prevent some pollutants from entering the building. Figure 9 presented the answers of respondents' ventilation choices under serious outdoor pollution. Residents from SC, C, and HSWW regions reported a high preference on mechanical ventilation, and none of them preferred using opening window for ventilation. As a comparison, $71.4 \%$ and $40 \%$ of the respondents in $\mathrm{M}$ and HSWW regions still preferred natural ventilation under polluted outdoor condition. The reasons for the distinction may be due to the difference in pollutant level among regions. According to the data from China National Environmental Monitoring Station, Environmental Monitoring of China (http://datacenter.mep.gov.cn/), the 2017 annual average concentration level of the monitored cities for SC, C, 
$\mathrm{HSCW}, \mathrm{M}$, and $\mathrm{HSWW}$ regions were $63 \mathrm{ug} / \mathrm{m} 3,70$ $\mathrm{ug} / \mathrm{m} 3,44 \mathrm{ug} / \mathrm{m} 3,22 \mathrm{ug} / \mathrm{m} 3$, and $35 \mathrm{ug} / \mathrm{m} 3$, respectively. Thus, the "heavy pollution" scenario perceived by residents in M and HSWW regions may be much lighter than the those perceived by residents in other regions.

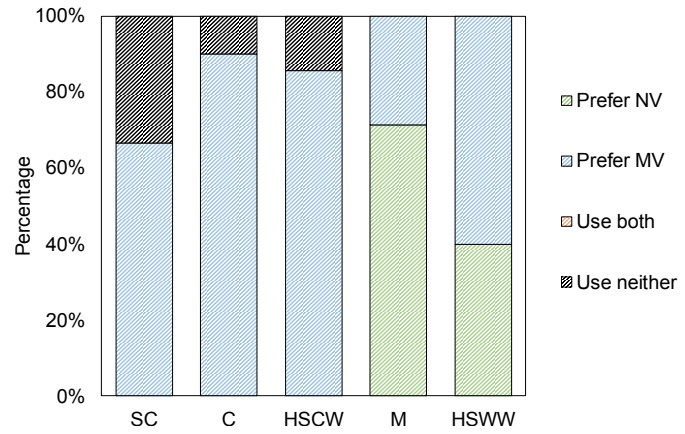

Fig. 9. Answers of ventilation usage pattern under heavy outdoor pollution for different climate zones.

\subsubsection{Reasons for not using natural and mechanical ventilation}

The last two questions in the questionnaire investigate the reasons when natural and mechanical ventilations were not used. Because the answers did not exhibit a clear regional pattern, we summarized the responses from all climate regions in two pie charts. Figure 10(a) shows that the highest percentage of the reason for not using windows for ventilation was outdoor pollution (42\%), followed by thermal discomfort (30\%) and outdoor noise $(28 \%)$. For mechanical ventilation, the three most selected reasons were the increased energy bills $(33 \%)$, system noise $(30 \%)$, and ineffectiveness of mechanical system in ventilation $(23 \%)$. Thermal discomfort only took $7 \%$ of the overall choices, which may reflect the fact that generally, mechanical system did not cause thermal discomfort. Besides the provided options, some respondents indicate that the need for regular filter replacement was an obstacle for using the mechanical ventilation system.
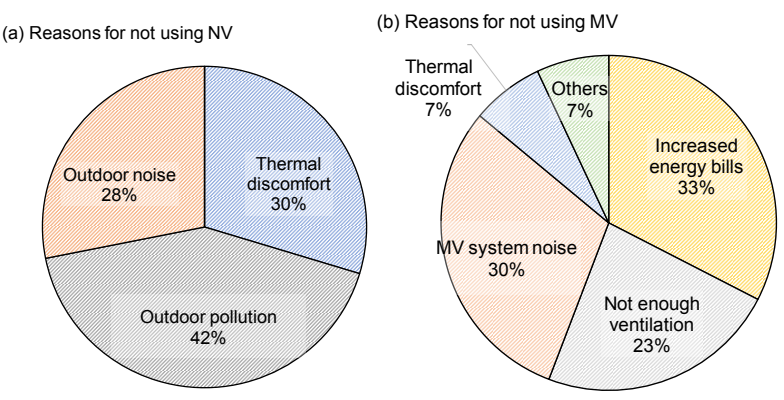

Fig. 10. Reasons for not using (a) the windows for ventilation; (b) mechanical system for ventilation

\section{Discussion}

\subsection{Thermal comfort, health, and energy saving as motivations of ventilation behavior}

This section proposes the three underlying motivations of the ventilation behaviors, which is thermal comfort, health, and energy saving.

Occupants' state of thermal comfort is based on instant perceptions of their thermal sensation. As a result, thermal comfort directly influences people's ventilation behavior. On the other hand, occupants do not immediately experience the adverse consequences of insufficient ventilation on health, such as asthma, allergy, or the sick building syndrome (SBS). However, people learnt from experience and public education that ventilation is beneficial to health. As a result, people's concern for health is an indirect motivation for their ventilation behaviors. Mechanical ventilation system causes less thermal discomfort than natural ventilation. If mechanical ventilation system is available, occupants may be willing to fulfill their needs for healthy indoor air quality at the cost of energy expenditure by using mechanical ventilation.

(a) When only NV is available

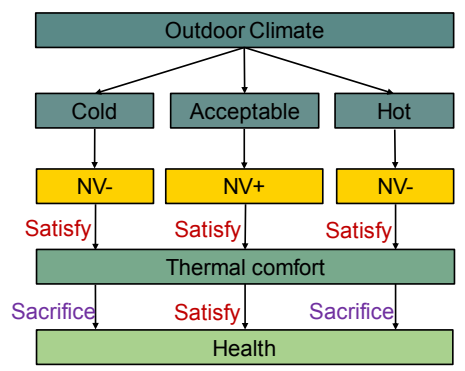

(b) When both NV and MV are available

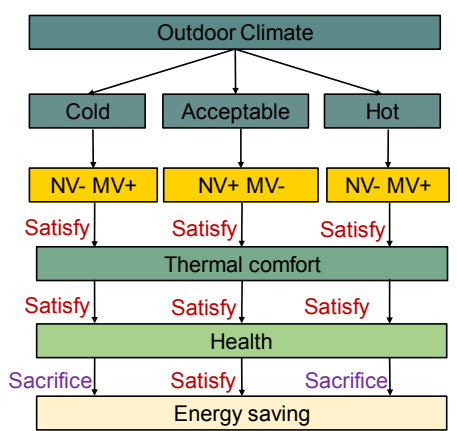

Fig. 11. The impacts of thermal comfort, health, and energy saving on ventilation behaviors under cold, acceptable, and hot outdoor climates for (a) naturally ventilated buildings; (b) buildings with both natural and mechanical ventilation options.

Figure 11 assumes that people prioritize thermal comfort requirements over health needs. As shown in Figure 11(a), when opening a window is the only approach of ventilation, people would reduce natural ventilation to avoid thermal discomfort when the outdoor is too cold or too hot, without addressing the possible adverse health effects of insufficient ventilation. When mechanical ventilation is available in addition to natural ventilation, as shown in Figure 11(b), people are willing to spend on energy to increase the mechanical ventilation usage and compensate the reduced natural ventilation. Finally, on occasions when the outdoor climate is suitable for natural ventilation, people will consider 
energy saving opportunities and reduce mechanical ventilation usage and use more natural ventilation.

\subsection{Strategies for designing and achieving healthy, thermally comfortable, and energy efficient ventilation in buildings}

Figure 12 provides a framework to design and achieve healthy, comfortable, and energy efficient ventilation in buildings. Firstly, the amount of required ventilation is determined on the basis of emission rates and health risks of pollutant. The emission rates of pollutants are characterized by the features of emission sources. In addition to emission rates, the health risks of pollutants may be investigated via toxicology studies and epidemiology evidences to set the exposure limits of pollutants. After knowing the emission rates and health risks of pollutants, it is also necessary to know if the natural ventilation is sufficient to dilute the indoor pollutant concentration to an acceptable level. If not, mechanical ventilation should be used as compensation.

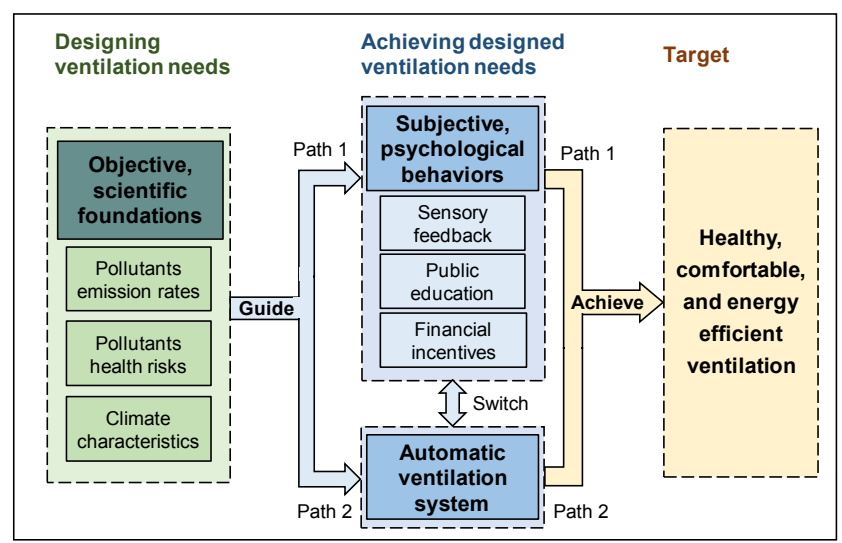

Fig. 12. A framework of designing and achieving healthy, comfortable, and energy efficient ventilation in buildings.

After the determination of ventilation requirement on the basis of objective scientific evidences, we have two ways of achieving the target. The first path is to guide the ventilation behaviors of occupants by providing sensory stimuli (such as visual feedback on indoor pollutant level and natural ventilation availability status), public education, or financial incentives. An alternative way to meet the ventilation needs is to develop and deploy an automatic ventilation system. By detecting indoor pollutant level and outdoor climate, the automatic ventilation system can calculate the amount of required ventilation and the availability of thermally comfortable natural ventilation. Then, the system can decide if natural, mechanical, or mixed ventilation should be used to achieve healthy, thermally comfortable, and energy efficient ventilation.

\section{Conclusions}

This study investigated the ventilation behavior in Chinese dwellings equipped with mechanical ventilation systems. Window-opening actions and mechanical ventilation system usages in 46 Chinese apartments in ten cities across five different climate zones were monitored for a year. Questionnaires were also distributed to understand residents' subjective choices. The following conclusions can be drawn from the analyses of the data.

- The average durations for natural and mechanical ventilations of the monitored apartments were 660 minutes (11.0 hours) and 429 minutes (7.2 hours), respectively.

- From north to south, as the climate became warmer, the natural ventilation duration increased, while the mechanical ventilation duration decreased.

- Summer was the season with the longest natural ventilation duration and shortest mechanical ventilation duration, while the trend in winter was reversed.

- With the increase of daily average outdoor air temperature, the duration of natural ventilation increased and the duration of mechanical ventilation decreased. However, in cold climate regions, the natural ventilation duration started to decrease when the daily average outdoor air temperature reached $24^{\circ} \mathrm{C}$.

- In cold climate region, probably due to the caused thermal discomfort, the usage of supply mechanical ventilation systems was much less than that of energy recovery ventilation systems.

- Large variations in natural and mechanical ventilation durations existed among different households. Occupants were inactive in changing their ventilation status in their dwellings.

Based on the results of ventilation behavior analyses, thermal comfort, health, and energy saving was proposed as the three motivations that drive the ventilation behavior. Occupants prioritize their thermal comfort needs over the requirement of healthy indoor air quality because thermal sensation is an instant perception while people do not immediately suffer from the adverse health effect of insufficient ventilation. However, occupants were willing to spend on energy expenditures when the health requirement can be fulfilled by mechanical ventilation that does not comprise thermal comfort. After presenting the motivations of ventilation behaviors, a framework was proposed to use objective scientific evidences to guide the subjective ventilation behaviors, or to design an automatic ventilation system, to achieve healthy, comfortable, and energy efficient ventilation in buildings.

\section{Acknowledgement}

This research was partially supported by the national key project of the Ministry of Science and Technology, China, on "Green Buildings and Building Industrialization" through Grant No. 2016YFC0700500. We would like to express our gratitude to Prof. Kailiang Huang from Shenyang Jianzhu University; Prof. Yiwen Jian from Beijing University of Technology; Prof. Yuexia Sun, Prof. Jingjing Pei, Prof. Hejiang Sun, and Prof. Xiong Shen from Tianjin University; Prof. Haiguo Yin from Xi'an University of Architecture and Technology; Prof. Hongwei Tan from Tongji University, Dr. Yao Gao from Shenzhen Institute of Building 
Research Co., Ltd.; and all the graduate students for their help in discussing results and collecting data for the study.

\section{References}

1. Q. Chen, Build. Environ. 44, 4 (2009) 848-858.

2. ASHRAE, ASHRAE Handbook (SI), Fundemental, American Society of Heating, Refrigerating and Airconditioning Engineers, Inc., Atlanta, 2009.

3. H.B. Rijal, P. Tuohy, M.A. Humphreys, J.F. Nicol, A. Samuel, J. Clarke, Energy Build. 39, 7 (2017) 823-836.

4. H.B. Rijal, Buildings 4, 3 (2014) 437-452.

5. R. Andersen, V. Fabi, J. Toftum, S.P. Corgnati, B.W. Olesen, Build. Environ. 69 (2013) 101-113.

6. S. Pan, Y. Xiong, Y. Han, X. Zhang, L. Xia, S. Wei, J. Wu, M. Han, Build. Environ. 133 (2018) 41-50.

7. W. Liu, D. Yang, X. Shen, P. Yang, Build. Environ. 135 (2018) 142-152.

8. L. Lan, X.L. Qian, Z.W. Lian, Y.B. Lin, Indoor air, 28, 1 (2018) 135-145.

9. L. Lan, Z. Zhai, Z. Lian, Build. Environ. 132 (2018) 319-326.

10. H. Liu, Z. Lian, Z. Gong, Y. Wang, G. Yu, Build. Environ. 135 (2018) 104-111.

11. H. Wang, L. Sun, H. Guan, S. Hu, Energy Build. 158 (2018) 1625-1631.

12. J.S. Park, H.J. Kim, Energy Build. 50 (2012) 19-25.

13. Ministry of Housing and Urban-Rural Development of the People's Republic of China, Thermal design code for civil building GB50176-2016, China Architecture and Building Press, Beijing, 2016. (In Chinese).

14. United States Department of Energy, Whole house ventilation.

https://www.energy.gov/energysaver/weatherize/ven tilation/whole-house-ventilation.

15. China Meteorological Administration, Division of Climatic Season QX/T 152-2012, China Meteorological Press, Beijing, 2012 (in Chinese).

16. National Bureau of Statistics of China, Per capita disposable annual income of urban households. http://data.stats.gov.cn.

17. D. Lai, S. Jia, Y. Qi, J. Liu, Build. Environ. 142 (2018) 234-243 